\title{
Safety and efficacy of vaginal misoprostol versus transcervical foley catheter and intravenous oxytocin for induction of labour
}

\author{
Ernest O. Orii \\ Dept Obs/Gyn \& Perinatology, Obafemi Awolowo University, \\ Ile-Ife Nigeria
}

\begin{abstract}
Introduction: A variety of drugs were used for induction of labour, but only oxytocin and prostaglandins have survived critical test of effectivity with a minimum of side effects for mother and child. The objective of this study is to compare efficacy and safety of vaginal misoprostol with transcervical Foley's catheter and intravenous oxytocin for induction of labour.

Methods: Eighty women at term gestation with the Bishops score $<4$ with various indications for labour induction were randomly allocated to receive 25 microgram misoprostol vaginally 4 hourly (maximum 6 doses) or transcervical Foley's catheter with intravenous oxytocin ( $2 \mathrm{mU} /$ minute to a maximum of $32 \mathrm{mU} /$ minute). There were 40 women in each group.

Result: In the misoprotol group induction delivery interval was significantly less (5.50 versus 15.0 hours) and successful induction significantly higher (95\% versus $75 \%$ ) as compared to catheter/oxytocin group. There were more cases of hyperstimulation with misoprostol; however neonatal outcome was similar in both groups. There were more vaginal delivery and less caesarean section in misoprostol compared to Foley's catheter/oxytocin group.

Conclusion: Vaginal misoprostol is highly effective, safe to administer as an agent for induction of labour. Key words: Vaginal misoprostol, intracervical catheter and oxytocin, induction of labour.
\end{abstract}

\section{Introduction}

In the past, a variety of drugs were used for induction of labour, but only oxytocin and prostaglandins have survived critical test of effectivity with a minimum of side effects for mother and child. ${ }^{1}$ However, labour induction in the presence of an unfavorable cervix is associated with an increased likelihood of prolonged labour. ${ }^{2}$ Due to this the use of cervical ripening agents prior to conventional methods of induction is now a standard practice..$^{2-5}$

In developing countries such as Nigeria, conventionally cheap and feasible method used for pre induction cervical ripening is transcervical Foley's catheter. However in recent years, misoprostol, a synthetic prostaglandin $\mathrm{E}_{1}$ analogue, originally developed as gastrocytoprotective agent, is being evaluated for term labour induction. Its advantages include effectiveness, low cost, stability at room temperature, and ease of administration. However the main concern with its use is excessive uterine response and studies had concentrated on finding the right dosage regimens that minimize this risk while maintaining efficacy $2,4,6$,

In this study the safety and efficacy of 25 microgram of vaginal misoprostol is compared with transcervical Foley's catheter and intravenous oxytocin for induction of labour.

\section{Methods}

This prospective randomized study was carried out at Victoria Specialist Hospital Ile-Ife and Ilesa Annexes between January 2003 to December 2006. Pregnant

Correspondence

Ernest O. Orji. MBBS, FMCOG, FWAC

Assoc Professor, Dept Obs/Gyn \& Perinatology, Obafemi Awolowo University, Ile-Ife Nigeria

Mobile: +2348033567451 E-mail:eoorjill@yahoo.com 
women who presented during this period with various indications for induction of labour with singleton fetus at term in cephalic presentation with intact membranes, Bishop score $\leq 4$ and volunteering to participate in the trial were included in the study. Exclusion criteria include women with previous caesarean section, multiple pregnancy, sickle cell abnormality, bronchial asthma, heart disease or known hypersensitivity to prostaglandins. Only women who consented for the trial after counseling were recruited. The primary outcome measure is the induction-delivery interval. The secondary outcome measures include the percentage of successful induction, rate of caesarean section, and the neonatal outcome.

The sample size for the comparison of independent mean was used ${ }^{7}$.

$\mathrm{n}=\mathrm{S}^{2}\left(-{ }^{1} \mathrm{~A}+\mathrm{Q}-{ }^{1} \mathrm{~B}(\mathrm{Zx}+\mathrm{Zp})^{2}\right.$ $\mathrm{Y}^{2}$

$\mathrm{S}^{2}=\quad$ Pooled estimate of the common variance of the two samples.

$\mathrm{QA}=$ The proportion of the total sample in sample A.

$\mathrm{QB}=$ The proportion of the total sample in sample B.

$\mathrm{Y}=\quad$ The difference detected between the means of two sample.

Using the computer system CPEA (computer programme for Epidemiologic Analysis) to calculate the sample size, it gave a minimum sample of 22 patients for each group. However, for this study, 40 patients were included in each group to make the result statistically significant. A total of 80 patients were recruited.

Women on misoprostal group received 25 microgram of misoprostol 4 hourly for a maximum of 6 doses. In the catheter/oxytocin group, a 16 F Foley's catheter was introduced just beyond the internal os and its ballon was inflated with $30 \mathrm{ml}$ of sterile water. Traction was applied by taping the distal end of the catheter to the medial aspect of thigh. This was done at 08.00 hours and the cervix was reassessed after 12 hours and induction of labour commenced with simultaneous oxytocin and fore-water amniotomy. The initial dose of oxytocin (Syntocinon Cadila Health Care Ltd) is $2 \mathrm{mU} /$ minute and escalated by $2 \mathrm{mU} /$ minute every 30 minutes till the women went into established labour (three contractions in 10minutes each lasting 45-60 seconds) or the maximum dose of $32 \mathrm{mU} /$ minute was reached.

Throughout the induction, fetal heart rate was monitored by a fetoscope and Doppler machine and uterine contractions monitored manually.

The main measure of efficacy was successful induction. Secondary outcome measures were number of deliveries within 24 hours, mode of delivery, and total dose of inducing agents required for delivery. The measures of safety included the uterine tachysystole, uterine hypertonus, abnormal fetal heart reading, incidence of meconium passage and the neonatal outcome. Baseline data included maternal age, parity, gestational age, labour induction and preinduction cervical score.

Analysis was performed using statistical software SPSS version 11.5. Continuous variables were compared using the Fisher's $\mathrm{Z}$ test and discrete data with the $\chi^{2}$ test. Level of significance was placed at $\mathrm{P}<0.05$.

\section{Results}

Forty women received misoprostol and 40 received transcervical Foley's catheter and intravenous oxytocin. Maternal demographic characteristics and indications for induction were similar in the two groups (Table I).

There was successful induction in 38 of the 40 women who used misoprostol compared to 30 among 40 women who used Foley's catheter with intravenous oxytocin $(\mathrm{P}=0.03)$. The mean induction delivery interval was

Table I. Demographic Characteristics and indications for labour induction

\begin{tabular}{lcc}
\hline Variable & $\begin{array}{c}\text { Misoprostol }(\mathrm{n}=40) \\
\text { mean } \pm \text { SD }\end{array}$ & $\begin{array}{c}\text { Catheter / Oxytocin }(\mathrm{n}=40) \\
\text { mean } \pm \text { SD }\end{array}$ \\
\hline Age (years) & $26.1(18-35)$ & $26.2(19-36)$ \\
Parity & $1.12(0-3)$ & $1.3(0-3)$ \\
Gestation (weeks) & $38.25(37-42)$ & $38.15(37-43)$ \\
Pre induction cervical score & $3(2-4)$ & $4(2-4)$ \\
Indication for induction & $25(62.5 \%)$ & $26(65 \%)$ \\
Post term pregnancy & $10(25 \%)$ & $5(12.5 \%)$ \\
Hypertension & $10(25 \%)$ & $9(22.5 \%)$ \\
Intrauterine growth retardation & $5(12.5 \%)$ & $5(12.5 \%)$ \\
\hline
\end{tabular}


significantly shorter in the misoprostol group (8.50 hours compared to 15 hours in Foley's catheter/ oxytocin group) $\mathrm{P}=0.002$. The mean dose of agent required for the induction was 75 microgram in misoprostol group and 30mU/minute of oxytocin. There were 4 cases of hypertimulation in misoprostol group and 2 cases with fetal distress compared to 3 cases with fetal distress in catheter/oxytocin group (Table 2).

Table 3 showed that more women achieved spontaneous vaginal delivery in misoprostol group (35) compared to 25 among catheter/oxytocin group $(\mathrm{P}=0.02)$. There were however more women who had caesarean section in catheter/ oxytocin group compared to misoprostol group (10 versus 2). $\mathrm{P}=0.03$.

The neonatal Apgar Scores and birth weights were similar in both groups (Table 4). Table 5 shows the dose requirements till delivery. In the misoprostol group 2 women delivered with 25 microgram of misoprostol while 12 required up to 125 microgram to be delivered. In 4 (10\%), a maximum dose of 150 microgram was administered and $2(5 \%)$ of them had emergency caesarean section due to fetal distress. In the Foley's catheter/oxytocin group had 2 women delivered with the dose of $8-12 \mathrm{mU} /$ minute and with increasing dosage requirement more women delivered vaginally. However 4 out of the 10 women received up to $26-30 \mathrm{mU} / \mathrm{minute}$ of oxytocin had emergency caesarean section while all the 6 women who received $30 \mathrm{mU} / \mathrm{minute}$ of oxytocin had emergency caesarean section (Table 5).

\section{Discussion}

In this study, successful induction occurred in $95 \%$ of misoprostol group compared to $75 \%$ in catheter/ oxytocin group $(\mathrm{p}=0.03)$. This is similar to the finding of other investigators. ${ }^{2,8}$ The mean induction delivery interval for misoprostol group was 8.50 hours compared to 15 hours among catheter/oxytocin group $(\mathrm{P}=0.002)$. This interval is shorter than that reported by other authors (11.58 hours versus 19.45 hours $)^{2}$. Progress of labour was also rapid with misoprostol group as compared to that of oxytocin leading to greater number of women delivering within 24 hours (90\% versus $70 \%$ ). This is slightly higher than the finding of others who reported $88 \%$ of women delivery within 24 hours in misoprostol group compared to $72 \%$ in catheter/ oxytocin group ${ }^{2}$. Our finding is slightly lower than the findings by Calistan et al in which $91.3 \%$ delivered within 24 hours with sublingual misoprostol ${ }^{9}$.

The main concern with misoprostol is the incidence of excessive uterine contraction, which appears to be dose related. Our study shows that the higher the dose of misoprostol the shorter is the induction-delivery interval, but higher is the incidence of uterine hyperstimulation. For instance hyperstimulation occurred in $10 \%$ of misoprostol group compared to none among catheter/oxytocin group.

Despite the relatively high incidence of hyperstimulation, it did not result in increase in caesarean section or poor Apgar scores. In short the neonatal outcome is better in the misoprostol group.

Table 2. Outcome of labour induction

\begin{tabular}{lccc}
\hline Variable & Misoprostol & Catheter/Oxytocin & P value \\
\hline Successful induction & $38(495 \%)$ & $30(75 \%)$ & 0.03 \\
Induction delivery interval in hours & $8.50(6.1-25.1)$ & $15.0(8.42-36.15)$ & 0.002 \\
Mean doses required range & 75 microgram $(50-150)$ & $30 \mathrm{ml} / \mathrm{minute}(8-36)$ & 0.001 \\
Hyperstimulation & $4(10 \%)$ & - & - \\
Fetal distress & $2(5 \%)$ & $3(7.5 \%)$ & - \\
\hline
\end{tabular}

Table 3. Mode of delivery

\begin{tabular}{lccc}
\hline Variable mode of delivery & Misoprostol $\mathrm{n}=40$ & Catheter/Oxytocin $\mathrm{n}=40$ & P value \\
\hline Spontaneous vaginal delivery & $35(875 \%)$ & $25(62.5 \%)$ & 0.02 \\
Caesarean section & $2(5 \%)$ & $16(25 \%)$ & 0.03 \\
Vacuum & $5(12.5 \%)$ & $5(12.5 \%)$ & 0.95 \\
Cephopelvic & $1(2.5 \%)$ & $2(5 \%)$ & 0.35 \\
Fetal distress & $2(5 \%)$ & $2(5 \%)$ & 0.65 \\
Cervical dystocia & 0 & $2(5 \%)$ & 0.35 \\
\hline
\end{tabular}


Table 4. Neonatal outcome

\begin{tabular}{lccc}
\hline & $\begin{array}{c}\text { Misoprostol } \\
\mathrm{n}=40 \text { mean } \pm \mathrm{SD}\end{array}$ & $\begin{array}{c}\text { Catheter/Oxytocin } \\
=40 \mathrm{mean} \pm \mathrm{SD}\end{array}$ & P value \\
\hline Birth weight $(\mathrm{kg})$ mean $($ range $)$ & $3.0(2.4-3.6)$ & $3.0(2.5-3.7)$ & $>0.05$ \\
Apgar scores at 1 minute & 7 & 7 & $>0.05$ \\
Apgar scores at 5 minutes & 9 & 9 & $>0.05$ \\
Apgar scores $<$ 7 at 5 minutes & $1(2.5 \%)$ & $2(5 \%)$ & $>0.05$ \\
Live births & $39(97.5 \%)$ & $38(95 \%)$ & $>0.05$ \\
Still births & $1(2.5 \%)$ & $2(5 \%)$ & $>0.05$ \\
\hline
\end{tabular}

Table 5. Dose requirement till delivery

\begin{tabular}{cccccc}
\hline \multicolumn{3}{c}{ Women entered (n=40) } & \multicolumn{3}{c}{ Women entered (n=40) } \\
\hline $\begin{array}{c}\text { Dose of oxytocin } \\
(\mathrm{mu} / \text { minute })\end{array}$ & $\begin{array}{c}\text { Delivered } \\
\text { Number }\end{array}$ & $\begin{array}{c}\text { Not delivered } \\
\text { Number }\end{array}$ & $\begin{array}{c}\text { Dose of } \\
\text { misoprostol }(\mathrm{mcg})\end{array}$ & $\begin{array}{c}\text { Delivered } \\
\text { Number }\end{array}$ & $\begin{array}{c}\text { Not delivered } \\
\text { Number }\end{array}$ \\
\hline $1-6$ & - & - & 25 & $2(5 \%)$ & - \\
$8-12$ & $2(5 \%)$ & - & 50 & $4(10 \%)$ & - \\
$14-18$ & $4(10 \%)$ & - & 75 & $6(15 \%)$ & - \\
$20-24$ & $8(20 \%)$ & - & 100 & $10(25 \%)$ & - \\
$26-30$ & $10(25 \%)$ & $4(10 \%)$ & 125 & $12(30 \%)$ & - \\
32 & $6(15 \%)$ & $6(15 \%)$ & 150 & $4(10 \%)$ & 2 \\
\hline Total & 32 & 8 & & 38 & 2 \\
\hline \multicolumn{7}{c}{}
\end{tabular}

In conclusion, the use of vaginal misoprostol as a cervical ripening and labour inducing agent is highly effective and preferable to Foley's catheter/oxytocin regime. Since the use of misoprostol is inexpensive and less cumbersome to use and esthetically better compared to insertion of Foley's catheter and oxytocin infusions we recommend that its use should be encouraged and widespread.

\section{References}

1. Lippert TH, Mueck AO. Labour induction with alternate drugs. J Obstet Gynaecol 2002;22(4):343

2. Jindal P, Gill BK, Tirath B. A comparison of vaginal misoprostol versus Foley's catheter with oxytocin for induction of labour. J Obstet Gynecol India. 2007, 57 (1) : 42-47.

3. Ferguson JE, Head BH, frank FH et al Misoprostol versus low-dose oxytocin for cervical ripening a prespective, randomized, double-masked trial. An J Obstet Gynaeul 2002. 187:273-280

4. Hofmeyr GJ, Gulmezoglu AM,Alfrirevic Z, Misoprostol for induction of labour: a systemic review. $\mathrm{Br} \mathrm{J}$ Obstet Gynaecol 1999;106:798-803.

5. Hofmeyr GJ, Gulmezoglu AM. Vaginal misoprostol for cervical ripening and induction of labour. Cochrane Database. Syst Rev 2003; issue Art No. CD000941.

6. Shetty A, Livingstone 1, Acharya s et at. A randomized comparison of oral misoprostol and vaginal prostaglandin $\mathrm{E}_{2}$ tablets in labour induction at ferm Br J Obstet Gynacol 2004; 111 : 436-440.

7. Galiger PM, Abramson JH. Sample size for comparison of proportion or mean. In: Computer Programme for Epidemiologic analysis. Hawai: Makapuu, Medical Press 1993; 131-141.

8. Wing DA, Ham D, Paul RH. A comparison of orally misoprostol with vaginally administered misoprostol for cervical ripening and labour induction. Am J Obstet Gynacul 1999, 180: 1155 60.

9. Calistan E, Bodur H, Ozeren S et al. Misoprostol 50 microgram subhngually versus vaginally for induction of labor at term: a randomized study Gynaecol Obstet Invest 2005 : 59 : 55 - 11 